
$\$$ Research Square
Preprints are preliminary reports that have not undergone peer review.
They should not be considered conclusive, used to inform clinical practice, or referenced by the media as validated information.

\title{
Age, gender, and residence differences in prevalence and patterns of multimorbidity among older Chinese: Evidence from Chinese Longitudinal Healthy Longevity Survey
}

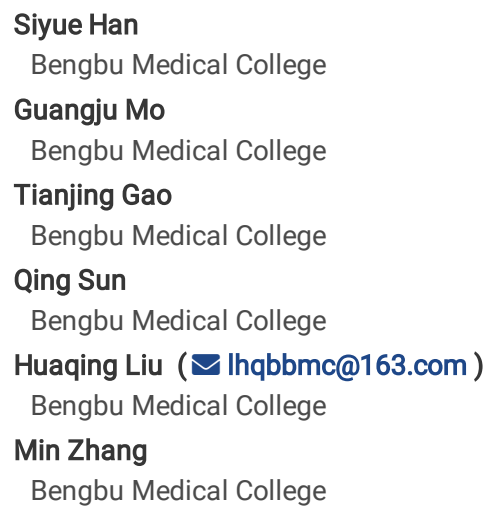




\section{Abstract}

Background With the dramatic acceleration of ageing in China, multimorbidity among the older adults has become increasingly common $₫$ which are associated with more functional decline and higher health care utilization and mortality. Understanding demographic differences of patterns of multimorbidity is in favor of making targeted intervention strategies. The purpose of this study was to reveal age- specific, gender- specific, and residence- specific prevalence and patterns of multimorbidity among older adults in China. Methods The present analysis is based on the 2018 wave of Chinese Longitudinal Health Longevity Survey (CLHLS). We selected 13 chronic diseases from the CLHLS survey, and information was collected based on self-report. Multimorbidity was defined as the coexistence of two or more chronic diseases from 13 chronic diseases in the same individual. Descriptive statistical analysis was used to examine multimorbidity according to age, sex, and residence. Patterns and trends of chronic disease pairs and multimorbidity were explored using association rule mining. Results 9,660 individuals aged $65-117$ years in the CLHLS were analyzed in this study. Overall, $74.4 \%$ of all participants had one or more morbidities, and $42.4 \%$ were multimorbid. The prevalence of individual chronic diseases ranged from $1.5 \%$ for cancer to $41.8 \%$ for hypertension, and each disease was often accompanied by one or more other chronic diseases. The prevalence of multimorbidity does not always increase with age. The subgroups with the highest prevalence of multimorbidity was $80-89$ years old (48.2\%), female (45.0\%) and urban (47.2\%) group. Prevalence of the hypertension- diabetes pattern decreases with age and is higher in women than in men. The prevalence of hypertension- depression pattern was at the highest among the $90-117$ years and rural older adults, while the other groups were hypertension-heart disease. Moreover, it was noteworthy that the multimorbidity rate of dyslipidemia is the highest at $95.5 \%$ among the 13 chronic diseases. Conclusions The prevalence of multimorbidity among older Chinese was substantial, and patterns of multimorbidity differed in age, sex, and residence. Future efforts are needed to identify possible prevention strategies and guidelines targeted demographic differences of multimorbid patients to promote health in older adults.

\section{Introduction}

Over the fifty years from 1950 to 2020 , the life expectancy of the world population has increased from 47 years old to 73.2 years old [1]. In 2019, the proportion of older adults in China aged 65 and over reached $12.6 \%$. The rate is increasing every year, indicating that China will enter a moderately ageing society in the near future [2]. In China, the prevalence of hypertension, diabetes, and hypercholesterolemia was $58.3 \%$, $19.4 \%$, and $10.5 \%$, respectively among people aged $\geq 60$ years, and up to $75.8 \%$ who had at least one chronic disease [3]. The concept of multimorbidity is commonly defined as the co-occurrence of multiple chronic or acute diseases and medical conditions within one person [4]. Since there is no uniform gold standard for the measurement of multimorbidity, a scoping review found that the prevalence of chronic multimorbidity in the population currently varies between $15.3 \%$ and $93.1 \%$ from 2012 to 2019 , depending on the number of chronic diseases examined or the population studied [5]. Consequently, the multimorbidity caused disability, functional decline, poor quality of life, and high health care utilization [6-7]. In addition, the risk of death has significantly elevated [8]. The old with multimorbidity have utilized five times more physician appointments than those without chronic conditions [8-9]. Research showed that older adults with multiple medical conditions have the highest unmet need for their hospitalization in China [10]. Although more and more people are beginning to acknowledge the seriousness of multimorbidity, however, the majority of health care systems are centered on treating individual diseases rather than looking at the complex network of diseases present in individual patients, which prevent the action from making full use of limited health resources to treat and manage the multimorbidity effectively.

In recent years, an increasing number of studies have begun to explore multimorbidity. However, to date, most studies have been limited to localized areas or descriptive analyses of multimorbidity. Moreover, general analytical methods tend to describe the epidemiology and cannot determine which diseases are more strongly associated with each other. Association Rule Mining (ARM), an important project in data mining, attempts to identify associations between as many attributes in a data set as possible and is now widely used in fields such as healthcare. Understanding demographic differences of patterns of multimorbidity is in favor of making targeted intervention strategies. Our study aims to provide an updated estimation and exploration of multimorbidity patterns and its demographic differences among older adults living in longevity areas of China using representative national data with association rule mining to provide a scientific basis for multimorbidity management guidelines, as well as to facilitate the design and implementation of better healthcare systems for patients with multimorbidity.

\section{Methods}

\section{Data Source and Study Population}

Data came from the Chinese Longitudinal Healthy Longevity Survey (CLHLS), a widely representative cohort survey conducted by the center for healthy ageing and family studies at Peking University and the Chinese center for disease control and prevention (http://opendata.pku.edu.cn/dataverse/CHADS). Beginning in 1998, this survey organized subsequent follow-up and recruitment of new participants in 2000, 2002, 2005, 2008, 2011, 2014, and 2018 covered 23 out of 31 provinces in China during the last decade. It has collected numerous data from a large sample of the senior citizens aged 80 and above, which provides information of the older adults. All information was obtained through face-to-face interviews by well-trained interviewers from the local centers for disease prevention and control. Detailed sampling procedures are available in elsewhere [11].

The information of this study was obtained from the seventh wave of the CLHLS in 2018. For eligibility, we excluded participants who were below 65 years old. Lastly, samples with missing values of major variables were also dropped. The final sample of 9,660 were analyzed in this study.

\section{Chronic disease and multimorbidity}

In this study, information on chronic diseases was based on self-report. Chronic diseases include hypertension, diabetes, heart disease, stroke or CVD (cardiovascular disease), respiratory disease (bronchitis, emphysema, pneumonia, and asthma), vision impairment (cataract and glaucoma), cancer, nervous system disease (Parkinson's disease, dementia, and epilepsy), gastrointestinal ulcer, rheumatoid arthritis (arthritis and rheumatism or rheumatoid disease), 
biliary disease, dyslipidemia, and depression. Depression in CLHLS was accessed by the 10-item Center for Epidemiologic Studies Depression (CES-D) scale [12], including eight negative oriented questions and two positive oriented questions. We recoded all responses in a four-scale metric, ranging from always (coded as 0 ) to often (coded as 1), sometimes (coded as 2), and seldom or never (coded as 3 ). Furthermore, the positively oriented questions, including "are you full of hope for future life?" and "do you feel as happy as you are when you are young?", were reversely coded before the summary ("seldom or never" coded as 0 , "sometimes" coded as 1 , "often" coded as 2 , and "always" coded as 3 ). The depression score ranges from 0 to 30 , with a higher score suggesting a greater degree of depressive symptoms. a cutoff of 10 was defined as diagnosed with depression. Multimorbidity was defined as the appearance of two or more aforementioned chronic diseases in an individual.

\section{Variables}

Personal information about the respondents was collected, including age, gender, and residence. Age was classified into three categories: 65 - 79 years, $80-89$ years, and 90-117 years. The residence was categorized as urban (city and town) and rural.

\section{Association Rule Mining (ARM)}

Association rule mining (ARM) is the process of exploring associations between items in data [13-14]. An association rule is an implication of the form $X \rightarrow Y$, where $X$ and $Y$ are disjoint, non-empty sets of codes. Code sets of $X$ and $Y$ are the antecedents and the consequents, respectively. The strength of an association rule ${ }^{X} \rightarrow{ }^{Y}$ can be measured by $S^{\text {upport }}$ (the prevalence of both $X$ and $Y$ co-occurring.) and confidence (the probability that $Y$ occurs given that $X$ is already present.). Lift is the deviation of the support parameter from what would be expected if $X$ and $Y$ were independent; lift $(X \rightarrow Y)=P(X, Y) / P(X) \times P(Y)$. When the lift value of $>1$, it implies $X$ and $Y$ are positively correlated. A higher lift indicates a stronger association between $X$ and $Y$. In the initial model, the minimum conditional support degree was set as $0.1 \%$, and the minimum threshold of confidence was set as $1.0 \%$, and a lift of $>1$ was selected.

\section{Statistical Analysis}

The statistical analyses were conducted using SPSS for Windows, version 22 (SPSS Inc., Chicago, IL, USA) and R version 4.1.2 (R Foundation for Statistical Computing, Vienna, Austria). Descriptive statistics were used to show the sociodemographic characteristics. Analyses were stratified by gender, age, and residence. Categorical variables were expressed as frequencies (percentage) and continuous as mean (Standard deviation, SD) or median (interquartile range, IQR). Frequency and percentages were reported for qualitative variables and were assessed by the Chi- square test or the fisher exact test, as deemed appropriate. Findings at corrected $P$-values of $<0.05$ were considered significant. Also, we plotted percentage stacked bar charts to reflect multimorbidity. We lastly modeled by the association rules to identify chronic disease multimorbidity patterns.

\section{Results}

\section{Descriptive statistics}

The final analytical sample included 9, 660 participants with a median age of 83 years (IQR74- 91 years), of which 3,878 (40.2\%) were in the $65-79$ years group, 2,679 (27.7\%) in the $80-89$ years group, and 3,103 (32.1\%) in the $90-105$ years group. $47.4 \%$ of participants were male, $56.3 \%$ lived in urban. Table 1 also showed that the prevalence of chronic disease and multimorbidity for older Chinese adults was $74.4 \%$, and $42.4 \%$, respectively. Of older adults with at least one morbidity, $57.0 \%$ had multimorbidity. The number of chronic diseases ranged from 0 - 12 . The mean number of chronic diseases in the multimorbidity- sample was 3.01 (SD 1.332). Multimorbidity was more common among the female, aged 80-89 years, and those who lived in urban ( $P<0.001)$. The detailed characteristics of the study population were showed in Table 1.

Table 1

Descriptive characteristics of the study samples under different health conditions.

\begin{tabular}{|c|c|c|c|c|c|}
\hline Variables & No chronic diseases $(n=2476)$ & Single disease $(n=3093)$ & $\begin{array}{l}\text { Multimorbidity } \\
(\mathrm{n}=4091)\end{array}$ & $\begin{array}{l}\text { Total } \\
(n=9660)\end{array}$ & $P$-value \\
\hline \multicolumn{5}{|l|}{ Age, n (\%) } & $<0.001$ \\
\hline $65-79$ years & $969(25.0 \%)$ & $1238(31.9 \%)$ & $1671(43.1 \%)$ & $3878(40.2 \%)$ & \\
\hline $80-89$ years & $566(21.1 \%)$ & $822(30.7 \%)$ & $1291(48.2 \%)$ & $2679(27.7 \%)$ & \\
\hline $90-117$ years & $941(30.3 \%)$ & $1033(33.3 \%)$ & $1129(36.4 \%)$ & $3103(32.1 \%)$ & \\
\hline \multicolumn{5}{|l|}{ Gender, n (\%) } & $<0.001$ \\
\hline Male & $1258(27.5 \%)$ & $1518(33.1 \%)$ & $1806(39.4 \%)$ & $4582(47.4 \%)$ & \\
\hline Female & $1218(24.0 \%)$ & $1575(31.0 \%)$ & $2285(45.0 \%)$ & $5078(52.6 \%)$ & \\
\hline \multicolumn{5}{|c|}{ Residence, n (\%) } & $<0.001$ \\
\hline Urban & $1252(23.0 \%)$ & $1621(29.8 \%)$ & $2567(47.2 \%)$ & $5440(56.3 \%)$ & \\
\hline Rural & $1224(29.0 \%)$ & $1472(34.9 \%)$ & $1524(36.1 \%)$ & $4220(43.7 \%)$ & \\
\hline
\end{tabular}




\section{Chronic disease and patterns of multimorbidity}

Table 2 showed the prevalence of 13 chronic diseases of participants, as well as the specific distribution by age, gender, and residence. The prevalence of hypertension had the highest prevalence of $41.8 \%$, followed by depression $(24.6 \%)$ and heart disease (17.2\%). The crude prevalence of diabetes, dyslipidemia and biliary disease was highest in the younger older group (65- 79 years). The stratification results by age groups indicated that the prevalence of the 13 chronic diseases was lowest in older adults aged 90-117 years, excepting for depression, and nervous system disease. The ranking of the prevalence of respiratory diseases increases with age (8th. vs. 7th. vs. 5th.). Differences were observed in the prevalence of chronic diseases among age groups $(P<0.05)$. Compared with females, males had a significantly higher prevalence of stroke or CVD and respiratory disease $(P<0.001)$. Respiratory disease and rheumatoid arthritis ranked the fourth and eighth, respectively, among males and, conversely, the seventh and fourth among the female population. There were no gender differences in diabetes, dyslipidemia, nervous system disease, and cancer ( $P>0.05)$. The prevalence of depression is comparable between urban and rural, and among the remaining diseases, urban is higher than rural older adults. No residence differences were observed in depression and nervous system disease $(P>0.05)$.

Table 2

Age-, gender- and residence -specific distributions of 13 chronic diseases of participants.

\begin{tabular}{|c|c|c|c|c|c|c|c|c|c|c|c|}
\hline \multirow[t]{2}{*}{ Rank } & \multirow[t]{2}{*}{ Chronic disease } & \multirow[t]{2}{*}{ Total } & \multicolumn{3}{|l|}{ Age } & \multirow{2}{*}{$\begin{array}{l}P \\
\text { value }\end{array}$} & \multicolumn{2}{|l|}{ Gender } & \multirow{2}{*}{$\begin{array}{l}P \\
\text { value }\end{array}$} & \multicolumn{2}{|l|}{ Residence } \\
\hline & & & $\begin{array}{l}65-79 \\
\text { years } \\
(n=3,878)\end{array}$ & $\begin{array}{l}80-89 \\
\text { years } \\
(n=2,679)\end{array}$ & $\begin{array}{l}90-117 \\
\text { years } \\
(n=3,103)\end{array}$ & & $\begin{array}{l}\text { Male } \\
(n=4,582)\end{array}$ & $\begin{array}{l}\text { Female } \\
(n=5,078)\end{array}$ & & $\begin{array}{l}\text { Urban } \\
(n=5,440)\end{array}$ & $\begin{array}{l}\text { Rural } \\
(n=4, \AA\end{array}$ \\
\hline 1 & Hypertension & $4035(41.8)$ & $1743(45.0)$ & $1238(46.2)$ & 1054(34.0) & $<0.001$ & 1825(39.8) & $2210(43.5)$ & $<0.001$ & $2440(44.9)$ & 1595( \\
\hline 2 & Depression & $2379(24.6)$ & $815(21.0)$ & $712(26.6)$ & $852(27.5)$ & $<0.001$ & 1010(22.0) & 1369(27.0) & $<0.001$ & $1350(24.8)$ & $1029(2$ \\
\hline 3 & Heart disease & 1662(17.2) & $682(17.6)$ & $548(20.5)$ & $432(13.9)$ & $<0.001$ & 707(15.4) & $955(18.8)$ & $<0.001$ & 1119(20.6) & $543(12$ \\
\hline 4 & $\begin{array}{l}\text { Rheumatoid } \\
\text { arthritis }\end{array}$ & 1289(13.3) & $568(14.7)$ & $416(15.5)$ & $305(9.8)$ & $<0.001$ & $453(9.9)$ & $836(16.5)$ & $<0.001$ & 799(14.7) & $490(11$ \\
\hline 5 & $\begin{array}{l}\text { Vision } \\
\text { impairment }\end{array}$ & 1367(14.2) & 435(11.2) & $433(16.2)$ & $499(16.1)$ & $<0.001$ & $553(12.1)$ & $814(16.0)$ & $<0.001$ & $960(17.7)$ & $407(9$. \\
\hline 6 & Stroke or CVD & 1014(10.5) & $432(11.1)$ & $338(12.6)$ & 244(7.9) & $<0.001$ & $535(11.7)$ & 479(9.4) & $<0.001$ & $665(12.2)$ & $349(8$. \\
\hline 7 & $\begin{array}{l}\text { Respiratory } \\
\text { disease }\end{array}$ & $991(10.3)$ & $342(8.8)$ & $321(12.0)$ & $328(10.6)$ & $<0.001$ & $580(12.7)$ & $411(8.1)$ & $<0.001$ & $611(11.2)$ & $380(9.1$ \\
\hline 8 & Diabetes & $953(9.9)$ & $509(13.1)$ & $289(10.8)$ & $155(5.0)$ & $<0.001$ & 424(9.3) & $529(10.4)$ & 0.06 & $695(12.8)$ & $258(6$. \\
\hline 9 & Dyslipidemia & $532(5.5)$ & $300(7.7)$ & $150(5.6)$ & $82(2.6)$ & $<0.001$ & $238(5.2)$ & $294(5.8)$ & 0.216 & $405(7.4)$ & $127(3$. \\
\hline 10 & $\begin{array}{l}\text { Gastrointestinal } \\
\text { ulcer }\end{array}$ & $466(4.8)$ & 205(5.3) & 152(5.7) & $109(3.5)$ & $<0.001$ & 198(4.3) & $268(5.3)$ & 0.032 & $288(5.3)$ & $178(4$. \\
\hline 11 & Biliary disease & $407(4.2)$ & $185(4.8)$ & $126(4.7)$ & $96(3.1)$ & 0.001 & 152(3.3) & $255(5.0)$ & $<0.001$ & $280(5.2)$ & $127(3$. \\
\hline 12 & $\begin{array}{l}\text { Nervous } \\
\text { system disease }\end{array}$ & $146(1.5)$ & $43(1.1)$ & $38(1.4)$ & $65(2.1)$ & 0.003 & $67(1.5)$ & $79(1.6)$ & 0.77 & $89(1.6)$ & $57(1.4$ \\
\hline 13 & Cancer & 146(1.5) & $69(1.8)$ & $44(1.6)$ & $33(1.1)$ & 0.042 & $74(1.6)$ & 72(1.4) & 0.478 & $100(1.8)$ & $46\left(1.1^{\prime}\right.$ \\
\hline
\end{tabular}

$N=9,660$ with complete information. * Significant at $P$-value 0.05 by Chi-square/ fisher exact test.

Figure 1 indicated the prevalence of multimorbidity for the 13 chronic diseases among the whole population. Multimorbidities above $90 \%$ were dyslipidemia (95.5\%) and biliary disease (90.2\%), and close to $90 \%$ were nervous system disease (89.7\%), diabetes (89.7\%), and stroke or CVD (89.3\%). Specifically, for older adults with dyslipidemia, more than $80 \%$ have two or more diseases, and more than $60 \%$ have three or more diseases. Depression has the lowest multimorbidity rate $(69.7 \%)$.

Table 3 showed the 10 most prevalent binary combinations by age, gender, and residence. The highest prevalence was found for the combination hypertension and heart disease (10.9\% in the total participants). A closer exploration of these 10 combinations revealed that the major component of the most prevalent dyads is hypertension, accounting for $7 / 10$. Hypertension and depression were the most common combinations in the $90-117$ and rural older adults. In addition, the combination of hypertension and diabetes was the third most frequent dyad in multimorbid aged 65- 79 years (prevalence 14.6\%), whereas this combination ranked ninth in aged 90 years and above (prevalence 3.5\%), with the former being more than twice as common as the latter. The hypertensionrheumatoid arthritis was more prevalent in women than in men, whereas the hypertension-stroke or CVD was more prevalent in men. Overall, the prevalence of binary combinations was all higher in urban than in rural participants. In particular, for some combinations, such as hypertension- visual impairment, hypertension- diabetes, and heart disease- visual impairment, the prevalence was more than twice as high in urban than in rural areas. 
Table 3

Patterns of multimorbidity of chronic conditions among the study population.

\begin{tabular}{|c|c|c|c|c|c|c|c|c|c|}
\hline Rank & Patterns of multimorbidity & $\begin{array}{l}\text { Total } \\
(n=9,660)\end{array}$ & $\begin{array}{l}65-79 \\
\text { years } \\
(n=3,878)\end{array}$ & $\begin{array}{l}80-89 \\
\text { years } \\
(n= \\
(n, 679)\end{array}$ & $\begin{array}{l}90-105 \\
\text { years } \\
(n= \\
3,103)\end{array}$ & $\begin{array}{l}\text { Male } \\
(n= \\
4,582)\end{array}$ & $\begin{array}{l}\text { Female } \\
(n=5,078)\end{array}$ & $\begin{array}{l}\text { Urban } \\
(n=5,440)\end{array}$ & $\begin{array}{l}\text { Rural } \\
(n= \\
4,220)\end{array}$ \\
\hline \multicolumn{10}{|c|}{ Morbidity dyads, n (\%) } \\
\hline 1 & $\begin{array}{l}\text { Hypertension + Heart } \\
\text { disease }\end{array}$ & 1051(10.9) & $445(11.5)$ & $355(13.3)$ & $247(8.0)$ & $429(13.7)$ & $618(16.6)$ & 746(13.7) & $301(7.1)$ \\
\hline 2 & Hypertension + Depression & 1032(10.7) & $381(9.8)$ & $351(13.1)$ & 299(9.6) & 426(13.6) & $605(16.3)$ & $640(11.8)$ & $391(9.3)$ \\
\hline 3 & $\begin{array}{l}\text { Hypertension + Vision } \\
\text { impairment }\end{array}$ & $744(7.7)$ & $269(6.9)$ & $246(9.2)$ & $228(7.3)$ & 299(9.5) & $444(11.9)$ & $554(10.2)$ & $189(4.5)$ \\
\hline 4 & Hypertension + Diabetes & $691(7.2)$ & $354(9.1)$ & $228(8.5)$ & $109(3.5)$ & $302(9.6)$ & $389(10.5)$ & $509(9.4)$ & $182(4.3)$ \\
\hline 5 & $\begin{array}{l}\text { Hypertension + Rheumatoid } \\
\text { arthritis }\end{array}$ & $684(7.1)$ & $309(8.0)$ & 237(8.8) & $138(4.4)$ & $228(7.3)$ & $456(12.3)$ & $461(8.5)$ & $223(5.3)$ \\
\hline 6 & $\begin{array}{l}\text { Hypertension + Stroke or } \\
\text { CVD }\end{array}$ & $641(6.6)$ & 293(7.6) & 211(7.9) & $136(4.4)$ & $320(10.2)$ & $320(8.6)$ & $447(8.2)$ & 193(4.6) \\
\hline 7 & Depression + Heart disease & $475(4.9)$ & $188(4.8)$ & $174(6.5)$ & 112(3.6) & $183(5.8)$ & 291(7.8) & $318(5.8)$ & $156(3.7)$ \\
\hline 8 & $\begin{array}{l}\text { Hypertension + Respiratory } \\
\text { disease }\end{array}$ & $423(4.4)$ & 149(3.8) & $141(5.3)$ & $133(4.3)$ & $238(7.6)$ & 185(5.0) & 295(5.4) & 128(3.0) \\
\hline 9 & $\begin{array}{l}\text { Heart disease + Vision } \\
\text { impairment }\end{array}$ & $416(4.3)$ & 133(3.4) & $142(5.3)$ & $140(4.5)$ & $166(5.3)$ & $249(6.7)$ & $334(6.1)$ & $81(1.9)$ \\
\hline 10 & $\begin{array}{l}\text { Depression + Rheumatoid } \\
\text { arthritis }\end{array}$ & $390(4.0)$ & $158(4.1)$ & $133(5.0)$ & $99(3.2)$ & $125(4.0)$ & $265(7.1)$ & $249(4.6)$ & $141(3.3)$ \\
\hline
\end{tabular}

\section{Association rules of chronic disease}

After executing the association rules mining, we obtained the association rule results by age, gender, and residence (see Additional File 1 for complete data for different subgroups). Then, we filtered the rules with support $>1.0 \%$ and confidence $>50.0 \%$. The final number of antecedents obtained has a minimum of 1 and a maximum between 4 and 7. Table 4 showed how these association rules were organized. Comparing the results above, in general, the group with higher prevalence also had a higher number of association rules. The ARM analysis by different groups resulted in largely similar multimorbidity patterns. The results showed (see Additional File 1) that hypertension ( $73.3 \%$ vs $63.8 \%$ vs $78.3 \%$ ) and heart disease ( $23.3 \%$ vs $28.7 \%$ vs $13.0 \%$ ) were common consequent rules in all three age groups. In addition to these common consequents were diabetes for the younger older group (65-79 years) and visual impairment for the $90-117$ years group. For the 80-89 years age group, rheumatoid arthritis and depression were included in the consequent. The strongest multimorbidity outcomes for the three age groups were dyslipidemia+ heart disease + hypertension $\rightarrow$ diabetes + dyslipidemia+ rheumatoid arthritis $\rightarrow$ diabetes and hypertension+ respiratory disease+ visual impairment $\rightarrow$ heart disease. The consequent rule for men is only hypertension or heart disease, while women have diabetes, vision impairment, and rheumatoid arthritis on top of that. The rural had only hypertension in the consequent, whereas the urbans had hypertension, heart disease, vision impairment, diabetes and rheumatoid arthritis. After sorting by magnitude of lift, the consequent with the largest elevation in each group was diabetes (65- 79 years, 80- 89 years, and female) or heart disease (90- 117 years, male, and urban) while the smallest were all hypertensive. Look closely at the rules for the first two age groups revealed that dyslipidemia is strongly associated with the development of heart disease and diabetes. And in the $90-117$ age group, respiratory disease showed a strong association with the occurrence of heart disease and hypertension (see Additional File 1, sheet 90-117 years).

Table.4 Association rules among different groups. 


\begin{tabular}{|c|c|c|c|c|c|c|c|}
\hline \multirow[t]{2}{*}{ Group } & \multirow{2}{*}{$\begin{array}{l}\text { Number of association rules } \\
\text { (filtered) }\end{array}$} & \multicolumn{2}{|c|}{ Support (\%) } & \multicolumn{2}{|c|}{ Confidence (\%) } & \multicolumn{2}{|l|}{ Lift (\%) } \\
\hline & & Minimum & Maximum & Minimum & Maximum & Minimum & Maximum \\
\hline \multicolumn{8}{|l|}{ Age, $n$} \\
\hline 65- 79 years & 60 & 1.01 & 11.47 & 50.50 & 94.12 & 1.21 & 4.04 \\
\hline 80- 89 years & 94 & 1.01 & 13.25 & 50.50 & 93.75 & 1.14 & 4.78 \\
\hline 90- 117 years & 23 & 1.03 & 7.96 & 51.06 & 82.14 & 1.52 & 5.15 \\
\hline \multicolumn{8}{|l|}{ Gender, n } \\
\hline Male & 34 & 1.00 & 9.36 & 50.33 & 82.18 & 1.26 & 3.82 \\
\hline Female & 80 & 1.00 & 12.17 & 50.37 & 91.36 & 1.57 & 5.21 \\
\hline \multicolumn{8}{|l|}{ Residence, $n$} \\
\hline Urban & 118 & 1.01 & 13.71 & 50.27 & 92.22 & 1.13 & 4.35 \\
\hline Rural & 12 & 1.11 & 7.13 & 51.89 & 81.48 & 1.37 & 2.26 \\
\hline
\end{tabular}

\section{Discussion}

This study examined the prevalence and pattern of multimorbidity in older adults by age, sex, and residence level based on a large national dataset in China. It can be seen that chronic disease and multimorbidity among older Chinese is a common public health issue. This study consists of 13 relative comprehensive chronic disease conditions including physical and mental illnesses, which are a reliable basis for exploring chronic diseases and their multimorbidity patterns. The finding indicated that $74.4 \%$ of the population had at least one of the 13 diseases and $42.4 \%$ suffered from multimorbidity, which was comparable to the results of a previous study [15]. The estimated prevalence of multimorbidity in this study is much lower than previous studies in other countries. For example, a study of 6101 older people in Irish showed a high prevalence of multimorbidity of $73.3 \%$ [16]. However, it is difficult to compare the prevalence rates generated by different studies due to differences in the types of diseases selected and the number of multimorbidities and the demographic characteristics of the samples.

Our study further assessed the multimorbidity patterns by age group, especially for aged 90 years and above that have not been mentioned in other studies. Some studies on multimorbidity have indicated that multimorbidity rates increase with age [17-18]. It is interesting that the prevalence of multimorbidity increased with age (43.1\% older adults aged $65-79$ years and $48.2 \%$ for aged 80 - 89 years), but no longer increased, and conversely, was lowest for longevity older adults aged $90-117$ years (36.4\%). A Taiwanese cross-sectional study was similar to our results on multimorbidity trends in different age groups (53.1\% vs. $64.3 \%$ vs. $45.7 \%$ ) [19]. Besides, a study based on multi-country population indicated that South Africa showed a unique pattern with a gradual decline in the prevalence of multimorbidity in adults with the age of over 65 years old. Poland, as well as Mexico, also began to see a decline in the rate of multimorbidity in people aged 70 years and older [20]. This discrepancy is likely associated with the relatively large proportion of the population over 90 years of age (32.1\%) in our study, and the lower prevalence of chronic and multiple diseases in these older adults, which contributed to this difference. It is also possible that older adults with multiple chronic conditions may have died or were unwilling to participate in the study. In addition, many participants aged 90 years or older did not even have access to a definitive diagnosis of a chronic disease due to financial and mobility constraints. By measuring the psychological status of older adults, we found that the rate of depression in older adults increases with age. Many existing studies have also included psychological disorders such as depression in the study of multiple diseases and studies have shown a bidirectional association between depression and multimorbidity. Multiple disorders and geriatric depression may also accelerate the processes of [21-22]. Future studies should investigate the role of depression in the association with clusters of multimorbid chronic diseases. In our study, the 65-79 years older adults had the highest prevalence of the hypertension-diabetes, which was trending younger. Recent studies have shown that the disease burden of diabetes in China is serious and there is an urgent need for greater intervention [23]. The slight gender differences found in this study regarding the multimorbidity of chronic diseases are consistent with van den et al [24]. All combinations of rheumatoid arthritis and visual impairment were more common in women, whereas stroke and respiratory diseases were more common in men, suggesting that a gender-specific disease spectrum for chronic disease management should be constructed for chronic disease control and intervention. We also found that the prevalence of multimorbidity was higher in the urban than those in rural, contrary to the results of another national study [25]. This may be due to the difference in the sample size of our study and the proportion of the population in urban and rural areas. Also, multimorbidity in the most socioeconomically deprived areas might occur 10-15 years earlier and 11-fold higher odds of physical and mental health disorders than those in affluent areas $[18,26]$. The relatively low prevalence in our study, with the exception of depression, may represent a rural under-diagnosis in these rural communities with low awareness of the disease and limited access to laboratory testing. However, the diagnosis of depression, which was based on ten questions face-to-face, increased the diagnosis of the disease. This underscores the need to focus our capacity building efforts in these areas.

We observed that among participants with $\geq 2$ chronic conditions, hypertension was present in almost all common multimorbidity patterns in different subgroups, as well as in the association rule results. One study by Ju-Hee Lee showed that the number of patients with hypertensive multimorbidities increases every year and grows more rapidly in older patients [27]. This strengthened the need for the prevention of hypertension to start long before the age of 65. The top 5 chronic diseases in terms of multimorbidity in this study were dyslipidemia, biliary disease, nervous system disease, diabetes, and stroke or CVD. Results also showed that although the prevalence of dyslipidemia is the ninth highest of the 13 chronic diseases, it has the highest multimorbidity rate, which means that older people with dyslipidemia are at great risk of having other complications. There are common behavioral risk factors among the diseases, e.g., poor dietary habits are risk factors for diabetes and can also lead to cardiovascular disease, hitting upon the need for change poor lifestyle before the age of 
65 [11]. In contrast, depression, which has the second highest prevalence rate in the entire population, has the lowest multimorbidity rate. This suggests that depression can also develop alone without other chronic conditions.

The greatest strength of this study is the adequate size and representative sample to investigate the multimorbidity patterns among the Chinese older population living in longevity areas. This study also had several limitations. Firstly, this article used cross-sectional data, which cannot observe the complexly changing relationship between multiple chronic diseases. Secondly, our study did not dig into the factors influencing multimorbidity, and further research is needed to investigate the influencing factors related to multimorbidity.

\section{Conclusion}

With the ageing of the population, the multimorbidity of chronic diseases among older adults in China will become increasingly severe and complex, resulting in an increased difficulty in multimorbidity management. The fact that more than two chronic diseases co-exist within an individual underline that it needs to take the integrated measures to simultaneously treat and manage increasing multiple and co-existing chronic diseases. Existing practice guidelines tend to manage single chronic diseases in isolation and might not meet the therapy and management of chronic diseases under different multimorbidity patterns. This study on multimorbidity patterns of chronic disease and screening for high prevalence patterns help to provide an entry point for research on multimorbidity etiology, as well as a reference for the subsequent development of treatment guidelines for high prevalence multimorbidity combinations and disease prevention and health management.

\section{Abbreviations}

\section{CLHLS}

Chinese Longitudinal Longevity Survey (CLHLS)

CVD

Cardiovascular disease

ARM

Association Rule Mining

\section{Declarations}

\section{Consent for publication}

Not applicable.

\section{Availability of data and materials}

Data are from the Chinese Longitudinal Healthy Longevity Survey 2018 which is a public, open access repository (https://opendata.pku.edu.cn).

\section{Competing interests}

The authors declare that they have no conflicts of interest.

\section{Funding}

The work was supported by the 512 Talent training Project of Bengbu Medical College (BY51201203).

\section{Acknowledgements}

The data used in this study was obtained from the Chinese Longitudinal Healthy Longevity Survey (CLHLS), which was managed by the Peking University Center for Healthy Aging and Development Studies. This survey was jointly funded by the National Natural Science Foundation of China (No. 71233001 and 71110107025), NIH (No. R01AG023627) and the United Nations Population Fund.

\section{References}

1. United Nations Population Fund (UNFPA) New York (NY): UNFPA; 2020. Life expectancy of world population 2020.

https://www.worldometers.info/demographics/life-expectancy. Accessed 2020 Oct 25.

2. China Statistical Yearbook, 2020. http://www.stats.gov.cn/tjsj/ndsj/2020/indexch.htm. Accessed on 26 April 2020.

3. Wang LM, Chen ZH, Zhang M, Zhao ZP, Huang ZJ, Zhang X, et al. [Study of the prevalence and disease burden of chronic disease in the elderly in China]. Zhonghua Liu Xing Bing Xue Za Zhi. 2019;40:277-83.

4. van den Akker M, Buntinx F, Knottnerus JA. Comorbidity or multimorbidity: what's in a name? A review of literature. European Journal of General Practice. 1996;2:65-70.

5. Chua YP, Xie Y, Lee PSS, Lee ES. Definitions and prevalence of multimorbidity in large database studies: A scoping review. International Journal of Environmental Research and Public Health. 2021;18:1-12.

6. Qin J, Theis KA, Barbour KE, Helmick CG, Baker NA, Brady TJ, et al. Impact of arthritis and multiple chronic conditions on selected life domains - United States, 2013. MMWR Morbidity and mortality weekly report. 2015;64:578-82. 
7. Ryan B, Allen B, Zwarenstein M, Stewart M, Glazier R, Fortin M, et al. Multimorbidity and mortality in Ontario, Canada: A population-based retrospective cohort study. Journal of Comorbidity. 2020;10:2235042X2095059.

8. Skinner HG, Coffey R, Jones J, Heslin KC, Moy E. The effects of multiple chronic conditions on hospitalization costs and utilization for ambulatory care sensitive conditions in the United States: A nationally representative cross-sectional study. BMC Health Services Research. 2016;16:1-8.

9. Zhang Y, Zhou L, Liu S, Qiao Y, Wu Y, Ke C, et al. Prevalence, correlates and outcomes of multimorbidity among the middle-aged and elderly: Findings from the China Health and Retirement Longitudinal Study. Archives of Gerontology and Geriatrics. 2020;90:104135.

10. Dhalwani NN, Zaccardi F, O'Donovan G, Carter P, Hamer M, Yates T, et al. Association between lifestyle factors and the incidence of multimorbidity in an older english population. Journals of Gerontology - Series A Biological Sciences and Medical Sciences. 2017;72:528-34.

11. Yin Z, Shi X, Kraus VB, Brasher MS, Chen H, Liu Y, et al. Gender-dependent association of body mass index and waist circumference with disability in the chinese oldest old: BMI and WC with Disability in Oldest old. Obesity. 2014;22:1918-25.

12. Andresen EM, Malmgren JA, Carter WB, Patrick DL. Screening for depression in well older adults: evaluation of a short form of the CES-D (Center for Epidemiologic Studies Depression Scale). Am J Prev Med. 1994;10:77-84.

13. Mahmoodi SA, Mirzaie K, Mahmoudi SM. A new algorithm to extract hidden rules of gastric cancer data based on ontology. SpringerPlus. $2016 ; 5$.

14. Peng M, Sundararajan V, Williamson T, Minty EP, Smith TC, Doktorchik CTA, et al. Exploration of association rule mining for coding consistency and completeness assessment in inpatient administrative health data. Journal of Biomedical Informatics. 2018;79:41-7.

15. Wang R, Yan Z, Liang Y, Tan ECK, Cai C, Jiang H, et al. Prevalence and patterns of chronic disease pairs and multimorbidity among older Chinese adults living in a rural area. PLoS ONE. 2015;10:1-15

16. Hernández B, Reilly RB, Kenny RA. Investigation of multimorbidity and prevalent disease combinations in older Irish adults using network analysis and association rules. Scientific Reports. 2019;9:1-12.

17. Forman DE, Maurer MS, Boyd C, Brindis R, Salive ME, Horne FMF, et al. Multimorbidity in Older Adults With Cardiovascular Disease. Journal of the American College of Cardiology. 2018;71:2149-61.

18. Van Den Akker M, Vaes B, Goderis G, Van Pottelbergh G, De Burghgraeve T, Henrard S. Trends in multimorbidity and polypharmacy in the Flemish-Belgian population between 2000 and 2015. PLoS ONE. 2019;14:1-12.

19. Hu RH, Hsiao FY, Chen LJ, Huang PT, Hsu WWY. Increasing age- and gender-specific burden and complexity of multimorbidity in Taiwan, 2003-2013: A cross-sectional study based on nationwide claims data. BMJ Open. 2019;9:1-10.

20. Garin N, Koyanagi A, Chatterji S, Tyrovolas S, Olaya B, Leonardi M, et al. Global Multimorbidity Patterns: A Cross-Sectional, Population-Based, MultiCountry Study. Journals of Gerontology - Series A Biological Sciences and Medical Sciences. 2016;71:205-14.

21. Read JR, Sharpe L, Modini M, Dear BF. Multimorbidity and depression: A systematic review and meta-analysis. Journal of Affective Disorders. 2017;221:36-46.

22. Triolo F, Harber-Aschan L, Murri MB, Calderón-Larrañaga A, Vetrano DL, Sjöberg L, et al. The complex interplay between depression and multimorbidity in late life: risks and pathways. Mechanisms of Ageing and Development. 2020;192:111383.

23. Wang L, Peng W, Zhao Z, Zhang M, Shi Z, Song Z, et al. Prevalence and Treatment of Diabetes in China, 2013-2018. JAMA. 2021;326:2498.

24. Van Den Bussche H, Koller D, Kolonko T, Hansen H, Wegscheider K, Glaeske G, et al. Which chronic diseases and disease combinations are specific to multimorbidity in the elderly? Results of a claims data based cross-sectional study in Germany. BMC Public Health. 2011;11:101.

25. Ma X, He Y, Xu J. Urban-rural disparity in prevalence of multimorbidity in China: A cross-sectional nationally representative study. BMJ Open. 2020;10:1-9.

26. Barnett K, Mercer SW, Norbury M, Watt G, Wyke S, Guthrie B. Epidemiology of multimorbidity and implications for health care, research, and medical education: A cross-sectional study. The Lancet. 2012;380:37-43.

27. Lee JH, Kim KI, Cho MC. Current status and therapeutic considerations of hypertension in the elderly. Korean Journal of Internal Medicine. 2019;34:68795.

\section{Figures}

\section{Figure 1}

Multimorbidity conditions of the top 10 chronic diseases in the CLHLS.

\section{Supplementary Files}

This is a list of supplementary files associated with this preprint. Click to download.

- AdditionalFile1.xls 